Fecha de recepción: octubre 2019

Fecha de aceptación: diciembre 2019

Versión final: noviembre 2021
Slow fashion en tiempo de redes sociales

María Mihanovich *

Resumen: El slow fashion es una corriente que viene haciéndose eco hace unos años e implica una forma de consumo más consciente. Donde el consumidor busca consumir menos cantidad y prendas más sustentables, con mejores procesos de confección, incluso saber quién confeccionó la prenda y de qué manera o en qué ambiente. Oponiéndose al consumo compulsivo. Entonces se cuestiona de qué manera se fusiona el slow fashion con la venta online y la venta en las redes sociales que constantemente bloggers o instegrammers de moda nos dicen qué vestir y cómo vestirlo. ¿Es posible que una marca de slow fashion o sostenible compita dentro de este sistema?

Palabras clave: Fast fashion - Slow fashion - moda - sostenible - ecología - sistema de la moda -tecnología - redes sociales - instagram - sustentable - orgánico - confección - cultivo de textiles - biotextiles.

[Resúmenes en inglés y portugués en las páginas 263-264]

${ }^{(*)}$ Diseño de Indumentaria y Textil, Universidad de Buenos Aires. Docente en la Universidad de Palermo, facultad de Diseño y Comunicación. Postgrado enDiseño de vestidos de novia y ceremonia, Instituto Europeo de Diseño sede. Creadora de la marca @sixfrid.

\title{
Slow fashion en tiempo de redes sociales
}

El slow fashion es una corriente que viene haciéndose eco hace unos años e implica una forma de consumo más consciente. Donde el consumidor busca consumir menos cantidad y prendas más sustentables, con mejores procesos de confección, incluso saber quién confeccionó la prenda y de qué manera o en qué ambiente. Oponiéndose al consumo compulsivo. Entonces se cuestiona de qué manera se fusiona el slow fashion con la venta online y la venta en las redes sociales que constantemente bloggers o instegrammers de moda nos dicen qué vestir y cómo vestirlo. ¿Es posible que una marca de slow fashion o sostenible compita dentro de este sistema?

Para poder hablar de Slow fashion o moda sostenible se debe hablar primero del sistema de Fast fashion moda rápida, ya que la primera surge en contra de la segunda. También se 
hablará sobre el sistema de la moda. El término Fast Fashion se inicia en 1980 con el surgimiento de los shoppings y las grandes cadenas multimarca como ZARA, Mango y H\&M, entre otras. Este proceso habla de una forma de consumo y de producción de la moda. En un principio había dos temporadas, primavera-verano y otoño-invierno y estas temporadas se exhibían en los grandes desfiles mostrando prendas exclusivas y costosas. Con el paso de los años surgieron los supermercados de moda como ZARA que toman lo que se expone en las pasarelas y las tendencias globales, copiando estas a bajo costo y salgan a producir en tiempo récord productos inspirados en esas tendencias. $Y$ al cabo de un mes o dos semanas aproximadamente, eso que se ah visto en las pasarelas ya estará en los locales, de forma masiva. Esto se repite constantemente y ya no se hace por grandes temporadas como se hacía en un principio, sino cada dos o tres semanas llegan a los locales y a las redes sociales nuevos productos. En la película The true cost movie año 2015 una periodista londinense comenta que se pueden encontrar 52 temporadas, generando mayor consumo y descarte. Este modelo de producción está descripto de la siguiente manera en el libro Vestir un Mundo Sostenible, de Miguel Ángel Gardetti y María Lourdes Delgado Luque quienes citan a Nueno, el cual considera que:

En el sector de la moda podemos distinguir cuatro modelos de producción: El más tradicional dura trescientos días, y comprende los procesos de diseño, moldería, tizada, pedido de tejidos, corte, confección y distribución. Luego un híbrido entre este modelo clásico, incorporando una producción más corta que garantiza la rotación de los productos en las tiendas. El tercer modelo de producción es el que opta por las prendas 'clásicas' que tienen una baja producción y, a su vez, también por las prendas Just in Time, que son susceptibles de rotar en periodos cortos, satisfaciendo necesidades y tiempos del mercado. Un cuarto modelo es el aplicado por marcas como Benetton, Zara, Gap o H\&M, que producen sus prendas en periodos que van desde los dos meses, o incluso, dos semanas (Gardetti y Delgado, año 2018, p. 88).

El cuarto modelo nombrado también es llamado Moda descartable donde el consumidor compra y tira las prendas que no tienen tanta durabilidad. Esto deja en claro que el consumidor está sujeto a los deseos del mercado y a la sobreproducción de productos y novedades constante. Como dice Miguel Ángel Gardetti y María Lourdes Delgado Luque en el libro Vestir un mundo sostenible.

La pérdida de la función simbólica de los productos que compramos es ampliamente anterior a su deterioro funcional. Es por esto que los consumidores compran cada vez más productos, lo que va generando una programación para el desecho. El cliente que compra un producto, independiente de su naturaleza, ya está predispuesto a deshacerse de él, en un tiempo breve (Gardetti y Delgado, año 2018, p. 90).

En el artículo del diario español El periódico (2017) dice que en España las personas consumen 34 prendas al año, un promedio de dos prendas nuevas al mes y al mismo tiempo 
descarta entre 12 y $14 \mathrm{~kg}$. De prendas, que luego se venden en los mercados de segunda mano.

En este proceso veloz el consumidor no tiene en cuenta como está hecha su prenda, ni es visible la cadena productiva, ni la contaminación, ni la forma de vivir de los confeccionistas o productores. Lo importante es que el costo sea bajo y que salga rápido al mercado para poder satisfacer sus necesidades, y a su vez generar un nuevo deseo de consumir. También esta manera de consumo está fomentada desde el marketing para generar constantemente nuevos deseos de consumir. Al tener un bajo costo llega a todos los consumidores y produce la necesidad de tener la prenda o producto nuevo, de tendencia. Como en esta sociedad queremos pertenecer a determinado segmento, el consumo de lo nuevo es necesario para formar parte de un grupo y por otro lado para cubrir las necesidades de vestir.

Afirmando esto se toma parte de un fragmento del libro, Vestir un mundo sostenible de Gardetti y Delgado (1980) "La moda puede definirse como un espectáculo, socialidad repetida, y que goza estéticamente de ella misma, juego del cambio por el cambio” (p. 104). Hoy por hoy el sistema de la moda cuenta como vestirse, propone formas de vida en relación al vestir e incluso las instagrammers y bloggers sugieren de qué manera usar cada prenda para estar a la moda. En estos tiempos veloces es cuando también se escucha un nuevo termino que es I see I buy, que significa veo y compro. Que trata de la compra online y por páginas como Instagram o los nuevos sistemas de Mercado Pago. Desde el 2000 que surgió en las grandes cadenas: el e-commerce. Una de las primeras en utilizarlo fue Victoria Secret. En este siglo la gente realiza casi todas sus compras online. Sólo necesita ver el producto en las redes y lo compra en cuestión de minutos. Dentro del e-commerce como dice el texto de Nuevas Tecnologías aplicadas a la Moda de José Antonio Guerrero, no sólo incluye la compra- venta sino todas esas actividades previas como el marketing, la búsqueda de información, contratación previa. Y mayormente el uso de internet es publicitario. Las nuevas tecnologías ayudan a que surja este nuevo sistema de comercio para un nuevo consumidor.

Esta nueva forma de comercio deja por afuera a los shoppings y tiendas. Ya no se hace publicidad explícita sino que se vende un estilo de vida a través de las redes. En instagram se enseña cómo se debe usar la ropa, como combinar los colores o qué prendas quedan bien para nuestro cuerpo. Esto lleva al consumidor a seguir cuentas de instagram que le enseñen algo nuevo, que tengan un valor detrás de la marca o que ofrezcan algo más que una prenda. Investigando en las redes sociales existe una IT Girl e instagrammer esponsoriada por varias marcas, que sale en revistas, va a eventos de moda, muestra una vida social y real o al menos muestran fotos como si fuera real. Esta instagrammer se llama Lil Miquela y es un holograma. Su identidad que era desconocida se rebeló en el 2018 por otra cuenta manejada por un robot y obligo a la influencer a contar quién era. Por lo tanto se da conocimiento hasta donde llega el marketing y el uso de las tecnologías en pos del consumo. Esta cuenta tiene 1,6millones de seguidores.

Esto implica que la forma de consumo y de venta ha cambiado de forma. En el libro de Benedetti, Marketing de redes sociales, detrás de escena habla del Marketing del siglo XX1 liderado por una generación de nativos del Smartphone.

En este mismo texto se cita a Paula Molinari quien manifiesta que "los millennials son 2.300 millones de jóvenes en el mundo, la generación más numerosa en la historia, que 
generará grandes cambios en el mundo del trabajo: en la concepción, los procesos, las estructuras, los puestos y en los perfiles valorados" (Benedetti, 2018).

Es por ello que hoy por hoy es imposible plantear una marca sin la visibilidad y la interacción en las redes sociales. En el blog de Mercado Shop en el texto de los Millennials y sus hábitos de consumo: plantean que esta generación en la Argentina realiza el 60\% de las compras on line y además tiene gran interés por los valores detrás de las marcas y la ecología.

En la página Online de Infobae (2019) realizaron un reporte sobre el consumo de los millennials en la era digital que plantea lo siguiente:

El informe indica que el $46 \%$ de la elección de compra de un millennial está determinada por la marca como una proyección de sus valores. La influencia de su entorno próximo también es significativa $(27,1 \%)$, pero casi al mismo nivel $(26,9 \%)$ de la opinión de celebrities e influencers, personas con las que no tienen una relación directa (Dillon, 2018, p. 1).

Esto quiere decir que el proceso de compra no pasa tanto por el producto en sí mismo. Sino por las opiniones, valores y visibilidad en las redes sociales.

Otra de las condiciones que valora esta generación es la ecología, para un millennial que una empresa tenga actividades eco friendly le da un valor agregado, la mayoría se muestra preocupado por el medio ambiente.

Esto invita a pensar y reflexionar lo que viene sucediendo hace unos años que se empezaron hacer visibles los casos de los talleres clandestinos en la Argentina y en el mundo, los malos tratos y las malas condiciones de producción. Comenzando el milenio en el libro No Logo, el poder de las marcas de Naomi Klein se puso en tela de juicio el sistema productivo. Ella plantea y se pregunta sobre las condiciones en las que fabricaban en China en los años noventa. Dejando a la luz un sistema de opresión y de malas condiciones de trabajo.

En la Argentina en el 2001 se funda la organización Social no Gubernamental La Alameda esta lucha contra el trabajo esclavo y la trata de personas entre otras cosas que realizan. La Nación y La Alameda (2016) dieron cuenta de esto y conforme los relevamientos de la organización social La Alameda se pudo saber que el 78\% de las prendas que se fabrican en la Argentina proviene de talleres clandestinos donde existen prácticas de trabajo forzoso, precario o esclavo. Éstas son confeccionadas por más de medio millón de personas. En la ciudad de Buenos Aires, este número alcanza aproximadamente a 30.000. Desde la Cámara Industrial Argentina de la Indumentaria C.I.A.I. respaldan estas cifras. Drescher (comunicación personal, 2016), presidente de la entidad, dice que "Se estiman en 25.000 las personas en la ciudad que trabajan en la informalidad y en 5000 las que lo hacen en condiciones de esclavitud". Esto si bien se informa no se visualiza, y la gente al no verlo no lo hace consciente o no lo internaliza. Pero que exista la esclavitud y condiciones de trabajo esclavo es realmente alarmante. Los realizadores de ropa deben buscar cambiar esto. Muchos diseñadores o marcas ni saben en qué condiciones se realizan sus prendas. En el documental de Morgan (2015) The true Cost Movie, se muestran las condiciones en las que realizan las prendas las grandes marcas y cuanta gente muere a causa de la moda. 
En este documental se muestra la tragedia de Bangladesh que sucedió en el año 2013, donde mil mujeres murieron tras el derrumbe de un edificio donde se confeccionaban prendas. Estas mujeres habían dado aviso del mal estado del edificio, pero las obligaron a volver a trabajar. Es por ello que en el documental se plantea el interrogante de que a que costo se hacen las prendas y que consecuencias tienen en las personas que trabajan para esas marcas. Un ejemplo de ello es la siguiente foto del documental donde muestra la situación en las que fabrican las mujeres, en este caso la imagen es impactante ya que se encuentra él bebe en el piso y no se sabe en qué estado está.

Una nueva agrupación que recorre el mundo llamada Fashion Revolution, empezó a realizar los carteles de ¿Quién hace tu ropa? Y muestra fotos de las costureras o quienes confeccionaron esa prenda o producto. Su lema es:

Fashion Revolution is a global movement calling for greater transparency, sustainability and ethics in the fashion industry. We want to unite the fashion industry and ignite a revolution to radically change the way our clothes are sourced, produced and purchased, so that what the world wears has been made in a safe, clean and fair way.

Su traducción es la siguiente

Fashion Revolution es un movimiento global para llamar a una mayor transparencia, sustentabilidad y la ética en la industria de la moda. Y que lo que vestimos y compramos se realice de una manera segura, limpia y justa. Por eso invitan a todos los de la industria a unirse a este movimiento.

En estos últimos años también se ven las corrientes como el Slow food, vegetarianismo, veganismo, el Mindfullness o ser conscientes de lo que se hace y de la forma en que se vive. Que invita a pensar que se come, que pensamientos se tienen, como se habita el espacio, como se habita el cuerpo y que se le da al cuerpo orgánico. De la mano de esta corriente y de la mano de la tendencia ecológica aparece el concepto Slow Fahion cuando por Kate Fletcher en el año 2007. Ella es profesora de Sostenibilidad, diseño y moda en el Centre for Sustainable Fashion de la Universidad de las Artes de Londres y ha escrito el libro Gestionar la sostenibilidad en la moda: diseñar para cambiar, año 2008. Actualmente es co-fundadora de Union of Concerned Researchers in Fashion que fue formada en el año 2018. Como se informa en la página online, de la Marca española Dear Tee en el escrito de Murillo (2016) ¿qué es el slow fashion?

El Slow Fashion no es una tendencia de temporada, sino más bien una filosofía de consumo responsable de ropa. El movimiento mentaliza y educa a los ciudadanos sobre el impacto de las prendas de vestir en el medio ambiente, el agotamiento de recursos y el impacto de la industria textil en la sociedad. Los materiales fomentados por esta filosofía son productos nobles que no contaminan el medio ambiente y que son biodegradables, todo lo contrario a los productos utilizados en la Fast Fashion. El Slow Fashion sigue las bases estable- 
cidas por el Slow Food. En este caso el movimiento de moda sostenible rechaza todo lo producido en cadena y promueve aquellos productos de calidad y perecederos (p. 1).

Así mismo en este artículo se dice que en el Slow fashion existen siete mandamientos que son los siguientes:

1. Oponerse a la moda producida en cantidades supra industriales.

2. Decantarse por productos artesanales para apoyar a las pequeñas empresas, el comercio justo y las prendas fabricadas localmente.

3. Fomentar el reciclado de prendas comprando ropa de segunda mano o vintage y donando las prendas que ya no se utilicen.

4. Elegir ropa fabricada con materiales sostenibles y producida éticamente.

5. Incorporar a nuestros armarios prendas clásicas y que duren más tiempo.

6. Hacer nuestras propias prendas: reparar, personalizar, alterar, para así alargar sus años de vida.

7. Disminuir el consumo de ropa: no comprar de forma compulsiva sino elegir prendas especiales y de máxima calidad.

Por eso se habla de moda lenta, la cual busca un sistema de consumo más responsable con el medio ambiente. Se espera que las prendas sean más duraderas, que el proceso productivo sea en buenas condiciones, que se hagan pocas cantidades y en con una excelente calidad.

En la revista Vogue de México (2017) en el artículo La filosofía del slow fashion se alza en latino américa dicen que:

En una colección slow, encontrarás que la manufactura es bajo condiciones adecuadas, materiales durables y siendo que por lo general están hechas a mano, tienen poca producción. Latinoamérica desde luego, está alzándose en la escena de la moda con pequeñas marcas que comienzan a darle una voz particular a distintas regiones. Gracias a la posibilidad de trabajar con artesanos, y la cada vez más reconocida compra local, el desarrollo de slow fashion está en un punto de ebullición importante (Castellanos, 2017, p. 5).

Las prendas que responden al slow fashion así como las verduras orgánicas o las carnes ecológicas son más costosas y lleva más tiempo producirlas. Ya que responden a un ritmo más orgánico y más humano. El ritmo físico del ser humano es más lento que lo que impone el mercado. Si se piensa en la gestación de una persona es de 9 meses y la evolución del ser humano que lleva años. ¿Por qué cambiar de ropa constantemente? El Slow fashion busca calmar un poco estas ansias del llenado de vacíos y actividades. Y no hacer las cosas porque están de moda, si no hacer y consumir lo que se necesita y se vaya a consumir cotidianamente. Esta corriente en vez de ser una tendencia le exige al mercado nuevas formas y nuevas tendencias. En la búsqueda de ejemplos sobre marcas Slow fashion se encontraron procesos interesantes y respuestas hacia esto que son realmente creativas. Por 
ejemplo se dice que lo nuevo en moda serán las prendas que no necesitan tanto lavado. Y la fibra que permite esto es la fibra de origen animal: La Lana. Posiblemente, se debería ver los procesos para que se pueda usar de manera más ligera en verano. La instagrammer Nadia Fornara, la creadora de la cuenta @theredvelvetlab con 9.339 seguidores, confirma lo anterior y da información de las marcas que están introduciendo un proceso sustentable y consciente con el medio ambiente. En su cuenta también invita a reflexionar al consumidor, en uno de sus posteos por ejemplo plantea el peligro al que está expuesto un empleado a la hora de blanquear las prendas con productos a base de cloro o la cantidad de petróleo que se utiliza para realizar fibras sintéticas.

Una de estas marcas que es argentina y sustentable es Nous Etudion, 71.300 seguidores. La diseñadora de esta marca es Romina Cardillo, ella se define como "Pionera de la moda sin género y comprometida con el slow fashion, su marca se comercializa en Europa a través del grupo Net-a-Porter" (Perez, 2018). En esta nota que le hace el Cronista también habla sobre los Biotextiles, que luego se hondará en el texto sobre ellos. Por otro lado Romina es vegana y traslada a sus prendas el no uso de fibras animales. Por eso utiliza materiales regenerados o fibras bio-degradables pero no de origen animal. Esta marca presentó en Barcelona una colección cápsula para Nike que lanzaba las zapatillas AirMax720 realizadas con materiales hechos de materiales reciclados.

También en este proceso de búsqueda se encuentra la marca @nativeshoes, 212.000 seguidores que realizó zapatillas $100 \%$ compostables y biodegradables. Y si bien se dice que tienen un alto costo, monetariamente hablando, estas zapatillas, tienen un bajo costo para el medio ambiente. Esto es lo que invita a pensar en esta nueva corriente y marca.

La marca @econylbrand con 18.800 seguidores crea productos regenerando redes del océano o nylon o regenera el uso de la alfombra roja. El último proyecto que hicieron es el icónico bolso de Prada regenerando filamentos de nylon. Este bolso cuya aparición se hará en el mercado en el 2021. Con lo cual se puede apreciar que grandes marcas de lujo se están asociando con las marcas de slow fashion para hacer productos sustentables y que no dañen a futuro el planeta.

A su vez marcas del fast fashion como H\&M realizaron una línea de colección llamada Concius que vende productos de algodones orgánicas. De esto se ha dicho que al menos si bien produce prendas masivamente tiene una parte consciente, o al menos trata de llegar a ese público. Lo mismo que Stella McCartney diseñadora de Adidas, plantea una línea dentro de su colección que es sustentable y en su página se muestra esto como vemos en la siguiente imagen, que se plantea el respeto por la naturaleza y las creencias de la marca en cuanto el respeto por el medio ambiente, usando fibras naturales como el algodón el cash mire y la viscosa.

Incluso una de las figuras que se publicita y da a conocer este movimiento en instagram es Livia Firth con 96.600 seguidores, ella es fundadora y creadora de @ecoage y fundadora de The Circle NGO. Esta última es una ONG de mujeres que empodera a mujeres. Y en su instagram ella invita a replantear el uso de la ropa. A guardar las prendas viejas y ser más conscientes de lo compramos, que al menos si se compra una prenda nueva, se le dé un mínimo treinta usos. Que si se piensa una prenda que gusta mucho se usa más de treinta veces. Ella está a favor de la reutilización de prendas de años anteriores, fomenta el guardado de las viejas ropas, y el vestirte de tus memorias con orgullo para resistir ante los dictadores 
de fast fashion. Invita a usar las prendas de las abuelas o incluso las ferias americanas. Actualmente en Argentina existen lugares que plantean la reutilización de las prendas usadas. Para darles un nuevo uso y para no dañar el planeta. Marcas que se encontraron que hacen esto son@elgalponderopaonline.

@datri_clothes_ba es una marca naciente Argentina con 1100 seguidores en instagram, que reutiliza prendas y genera un nuevo diseño atemporal que se pueda usar en varias estaciones y momentos. También se encontró a la marca @biotico_sustentable de materiales de descarte, envases y plásticos, hacen bolsos y prendas. Incluso vestidos de novia. La diseñadora desde el 2014 plantea prendas originales y artísticas.

@xinca_eco_shoes La empresa mendocina creada por tres amigos. Busca desde un comienzo resolver problemas sociales y/o ambientales. Por ello en la marca reutilizan desechos de gomas de autos y suman a trabajadores excluidos de la sociedad. A través de sus redes buscan mostrar no solo el producto sino procesos y conceptos como no solo buscar calidad en los productos que compran, sino asegurarse que existe calidad en las vidas de los que la fabrican.

En la Argentina en el año 2018 se creó la Asociación de Moda Sostenible creada por Alejandra Gougy junto a su hija, ambas de la marca Cosecha Vintage que reutiliza medias de nylon y a la Diseñadora Rosa Woudwyk, forman la comisión directiva. En la asociación busca reunir y contener a todos los diseñadores que creen productos de modo sostenible. Dentro de esta cámara se encuentran varias de las marcas argentinas que se nombraron, también @reinventandoprendas que genera nuevos diseños reutilizando prendas usadas. A su vez realizan talleres para que la gente aprenda a reinventar sus prendas. La Asociación de Moda sustentable lo que plantea y propone es que se haga más visible todo el trabajo que se realiza en el país en cuanto a la sustentabilidad.

Una de las consecuencias de la moda sostenible y slow fashion es la aparición desde el año 2013 de los bio textiles que se cree que cambiará la idea de textiles. Este proceso es el cultivo de organismos vivos, como bacterias, hongos y levadura para la generación de textiles. Como dice en el artículo On line de La Nación escrito por Maurello (2018), la primera en realizar pruebas de materiales y realizar prendas fue Suzzane Lee. Complementando esta información con el artículo On Line de Quinones (2013) sobre Suzzane Lee: Cultivando Moda. Los materiales que utiliza son principalmente: té verde, azúcar, bacterias y levadura de cerveza. A estos se los mezcla todos juntos, se los deja reposar y fermentar y al cabo de unos días se obtiene: una lámina transparente y gruesa de celulosa que después de un procedimiento de lavado y secado al aire libre, da paso a un nuevo tejido. Ella también creo una línea de colección llamada Bio-Couture que es un proyecto de diseño sustentable. En sus trabajos ella intenta hacer un replanteo de la moda y el uso de los materiales.

En la Argentina se encuentran dos jóvenes que han investigado en el tema y realizado biotextiles. Una es oriunda de Misiones: Verónica Bergottini genetista y Silvio Tinello diseñador industrial de Trelew, que han investigado y creado textiles BIO de una manera similar a la de Suzzane Lee, pero reutilizando materiales autóctonos como la yerba mate. Ambos han dado una charla Ted en enero del 2019, contando su historia personal y como llegaron a los Biotextiles. En esta charla ellos comienzan preguntándole al público: ¿De dónde salió la ropa que tienen puesta ese día, quién hizo su ropa? Explicando que van a contar otra forma de hacer ropa. Bergotini y Tinello (2019) explican cómo nace el Bio Diseño donde 
científicos y diseñadores emplean a los microorganismos como fábricas de materiales sustentables. Este proceso realizado en los laboratorios economiza tiempo, espacio y recursos naturales. Planteando que es posible la fabricación de ropa con materiales cultivados en un laboratorio y que luego del uso de la prenda esos materiales sean biodegradados. Y donde no existe el concepto de basura ya que esta es usada, fermentada y usada para generar nuevos textiles. En la siguiente imagen se puede ver ilustrado los materiales que se usan: mate más bacterias y levaduras para generar textiles.

En el artículo de La Nación On line sobre Biotextiles, Maurello (2018), también hace mención a la creación de biotextiles en diferentes ámbitos y para diferentes usos. Uno de estos usos sería el deporte, la fusión de ingenieros, diseñadores, arquitectos, biólogos, entre otros investigadores que lidera el Tangible Media Group en el Massachusetts Institute of Technology M.I.T. Media Lab, asociado con el Departamento de Ingeniería Química de ese instituto, el Royal College of Art y la empresa de indumentaria deportiva New Balance, estos generaron un material llamado BioLogic que es un material realizado con una capa de células vivas que permiten que unas pequeñas aletas que se abren ante la transpiración y vuelven a cerrarse cuando el cuerpo deja de sudar.

Dentro de estos procesos biológicos, de generación y cultivo de nuevos textiles se encuentra el cuero que realizó Tina Gorjanc, la diseñadora eslovena que estudió en la escuela Londinense Central Saint Martins. Ella realizó un cuero a partir del ADN de Alexander McQueen. De todos modos de estos textiles y experimentos sólo se han hecho pruebas y diseños exclusivos. Pero no dejan de ser procesos que podrían cambiar el origen de los materiales textiles y la forma de concebir las prendas. Pensando en un proceso a base de elementos sustentables que luego de su uso podrían ser reutilizados. En el texto de La Nación On line Maurello (2018) sobre Biotextiles: el cultivo de organismos vivos para la fabricación de telas, se cita a ambos argentinos que dicen lo siguiente Tinello considera que su aporte "es generar materiales que disminuyan o eliminen la contaminación" mientras que Bergottini considera que "la producción de estos textiles tiene un menor impacto en el medio ambiente. Hoy no se puede crear nada de manera responsable sin la sostenibilidad como punto de partida" (Maurello, 2018).

Lo interesante de estos procesos es que abren un nuevo paradigma en cuanto a la realización de textiles e incluso se replantea la moda sustentable $y$ Slow Fashion proponiendo desde la biología un cultivo de telas. Donde se fusiona moda, diseño y biología. Y principalmente dichos procesos sustentables, en la argentina, van de la mano de dos Millenials. Es por ello que incluso todos estos procesos son mostrados en las redes sociales, como en el caso de Verónica Bergottini la genetista misionera, muestra en su instagram @veronicabergottini, la cosecha, limpieza y tinción del biopolímero, futuro biotextil.

Esto mismo es sostenido por la diseñadora argentina Romina Cardillo (2018) en la entrevista mencionada en el diario On line El Cronista, diciendo lo siguiente:

Los textiles que nacen en el laboratorio hacen que la moda se mezcle con la ciencia, la biología y la tecnología. El futuro de la indumentaria va a seguir por ese camino: no se trata tanto de fijarse en el diseño sino en la materia prima. Reciclar y no contaminar está muy bien pero el futuro de la moda son los Biotextiles (p. 1). 
Todos estos avances abren un nuevo camino en el apasionante universo de la indumentaria, generando nuevas expectativas y posibilidades en el mundo de la moda.

\section{Conclusión}

A partir de la investigación realizada se puede concluir que, por un lado se está planteando un nuevo sistema de producción de moda en el mundo para un nuevo tipo y exigencias de consumidor. Los mayores consumidores son Millennials nacidos con las redes sociales. Por lo tanto es importante responder y llegar a ellos a través de las mismas redes y tecnologías. Las marcas de Slow fashion y sustentables se ven favorecidas en este proceso ya que a través de las redes pueden mostrar sus valores, procesos y formas ecológicas de trabajar. En vez de ser una dificultad es posible que sea una virtud para estas marcas y tengan mayor llegada a su público.

\section{Listado de Referencias Bibliográficas}

Benedetti, A. (2018). Marketing en redes sociales, detrás de escena. (3 ed.). Buenos Aires, Argentina: Editorial Temas.

Bergottini, V. y Tinello, S. (2019). Biotextiles, diseño y otras yerbas. [Charla TED]. Buenos Aires. Recuperado de: http://fronterajesuita.com.ar/biotextiles-diseno-y-otras-yerbas/

Castellanos Usigli, T. (2017). La filosofía del slow fashion se alza en latino américa. Mexico. Recuperado de https://www.vogue.mx/moda/estilo-vogue/articulos/slow-fashionlatinoamerica/7751

Dillon, J. (2018). Consumo en la era digital para los millennials: el nuevo lujo es vivir más que tener. Argentina. Recuperado de: https://www.infobae.com/tendencias/2018/09/29/ consumo-en-la-era-digital-para-los-millennials-el-nuevo-lujo-es-vivir-mas-que-tener/

EFE. (2017). Los españoles consumen 34 prendas y tiran hasta 14 kilos de ropa cada año. España. Recuperado de: https://www.elperiodico.com/es/sociedad/20170728/los-espanolesconsumen-34-prendas-y-tiran-hasta-14-kilos-de-ropa-cada-ano-6195530

Gardetti, M. y Delgado Luque, L. (2018). Vestir un mundo Sostenible, la moda de ser humanos en una industria polémica. Buenos Aires. Argentina: Editorial Argentina.

Maurello, E. (2018). Biotextiles: el cultivo de organismos vivos para fabricar telas. Argentina. Recuperado de https://www.lanacion.com.ar/moda-y-belleza/biotextiles-el-cultivo-deorganismos-vivos-para-fabricar-telas-nid2111290

Morgan, A y Ross, M. ( 2015). The True Cost Movie. [DVD] .Estados Unidos. Recuperado de: https://truecostmovie.com/about/

Morillo, M. (2016). Qué es el Slow Fashion?. España. Recuperado de https://www.deartee. com/blog/que-es-el-slow-fashion.html 
Pérez, L. (2018). Romina Cardillo de Nous Etudions: el futuro de la moda son los Biotextiles. Argentina. Recuperado de: https://www.cronista.com/clase/dixit/Romina-Cardillo-deNous-Etudions-El-futuro-de-la-moda-son-los-biotextiles-20181226-0002.html

Quinones, J. (2013). Suzzane Lee cultivando moda. Mexico. Recuperado de https://culturacolectiva.com/diseno/suzanne-lee-cultivando-moda

\title{
Otras fuentes consultadas
}

Cruz, L. (2018). Fast Fashion. España. Recuperado de http://knoow.net/es/cieeconcom/ marketing-es/fast-fashion

Fletcher, K. (2017). Slow fashion . Reino Unido. Recuperado de: https://theecologist. org/2007/jun/01/slow-fashion

Juncá, G. (2019) La tendencia 'slow fashion', la reivindicación de la moda sostenible. España. Recuperado de https://www.lavanguardia.com/economia/innovacion/20190110 /454053163147/zer-collection-slow-fashion-sostenibilidad-tecnocampus.html

Guerrero, J. (2009). Nuevas Tecnologías aplicadas a la moda, diseño producción, marketing y comunicación. Barcelona, España: Parramon.

Gwilt, A. (2014). Moda Sostenible. Barcelona, España: Gustavo Gili.

Volpe, G., (2016). Conoce la mente femenina que definió el movimiento "lento" hacia la moda sostenible. Madrid. Recuperado de: https://www.slowfashionnext.com/blog/2016/09/27/ kate-fletcher-la-pionera-del-slow- fashion/

\begin{abstract}
Slow fashion is a trend that has been expanding over the past years. A trend that implies a mindful consumption from the consumer. Where the overall production process is transparent and known to the consumer. The consumer chooses garments for quality and durability taking into account the overall process and environment.

Creating an opposition for the fast fashion. Then I wonder about the juxtaposition with social media fast fashion news. It's posible to be a slow fashion Brand in this contexts of quick social medias.
\end{abstract}

Keywords: Fast fashion - Slow fashion - fashion - sustainable fashion - ecology - fashion system - technology - social networks - instagram - sustainable - art and craft - organic handmade - confection - corporate social responsibility.

Resumo: A moda lenta é uma tendência que ecoou há alguns anos e implica uma forma de consumo mais consciente. Onde o consumidor procura consumir menos quantidade e peças mais sustentáveis, com melhores processos de fabricação, mesmo sabendo quem fez a peça e de que maneira ou em que ambiente. Opondo-se ao consumo compulsivo. Então me pergunto como a moda lenta se funde com as vendas on-line e as mídias sociais, que 
constantemente blogueiros ou instegrammers de moda nos dizem o que vestir e como vestir. É possível uma marca lenta ou sustentável competir dentro deste sistema?

Palavras chave: Moda rápida - moda lenta - moda sustentável - moda - ecologia - sistema de moda - tecnologia - redes sociais - instagram - sustentável - arte e artesanato - orgânicos - artesanais - confecção - responsabilidade social corporativa.

[Las traducciones de los abstracts fueron supervisadas por el autor de cada artículo] 